\title{
Synthesis of the ABCD trioxadispiroketal subunit of azaspiracid-1: An iodoetherification-dehydroiodination strategy for complex spiroketals
}

\author{
Xiaohua Li, Jialiang Li and David R. Mootoo* \\ Department of Chemistry, Hunter College, 695 Park Avenue, New York, NY 10021 and The Graduate Center, CUNY, \\ 3655 th Avenue, New York, NY 10016 \\ dmootoo@hunter.cuny.edu
}

General $\quad$ S1

Synthesis and physical data for new compounds $\quad$ S1

$\begin{array}{ll}\text { Synthesis and physical data for title compound } & \text { S14 }\end{array}$

Selected ${ }^{1} \mathrm{H}$ and ${ }^{13} \mathrm{C}$ NMR charts $\quad$ S16 


\section{Supporting Information}

\section{General}

${ }^{1} \mathrm{H}$ NMR spectra were recorded at $500 \mathrm{MHz}$ at ambient temperature with $\mathrm{CDCl}_{3}$ as the solvent unless otherwise stated. ${ }^{13} \mathrm{C}$ NMR spectra were recorded at $125.0 \mathrm{MHz}$ at ambient temperature with $\mathrm{CDCl}_{3}$ as the solvent unless otherwise stated. Chemical shifts are reported in parts per million relative to $\mathrm{CDCl}_{3}\left({ }^{1} \mathrm{H}, \quad 7.27 ;{ }^{13} \mathrm{C}, \quad 77.23\right)$, benzene- $\mathrm{d}_{6}\left({ }^{1} \mathrm{H}, \quad 7.16 ;{ }^{13} \mathrm{C}, \quad\right.$ 128.39). Data for ${ }^{1} \mathrm{H}$ NMR are reported as follows: chemical shift, multiplicity (ovrlp $\mathrm{m}=$ overlapping, $\mathrm{s}$ = singlet, $\mathrm{d}=$ doublet, $\mathrm{t}=$ triplet, $\mathrm{q}=$ quartet, $\mathrm{m}=$ multiplet , coupling constants and integration,. All ${ }^{13} \mathrm{C}$ NMR spectra were recorded with complete proton decoupling. Low and high-resolution mass spectra were obtained in the Hunter College Mass Spectrometry Laboratory using a Finnegan MAT-90 spectrometer. Optical rotations were recorded on an AUTOPOL III digital polarimeter at $589 \mathrm{~nm}$, and are recorded as $[\alpha]_{\mathrm{D}}{ }^{24}$ (concentration in grams $/ 100 \mathrm{~mL}$ solvent). Analytical thin layer chromatography was performed using $0.25 \mathrm{~mm}$ silica gel $60-\mathrm{F}$ plates. Flash chromatography was performed using 200-400 mesh silica gel (Scientific Absorbents, Inc.). Yields refer to chromatographically and spectroscopically pure materials, unless otherwise stated. All other reagents were purchased from Sigma-Aldrich, Lancaster, Alfa Aesar, and Strem Chemicals. Methylene chloride, acetonitrile, methanol, and benzene were purified by passing through two packed columns of neutral alumina (Glass Contour, Irvine, CA). All reactions were carried out in oven-dried glassware under an argon atmosphere unless otherwise noted. Arabic numbers are used for numbered compounds in the main manuscript. Roman numerals are used for synthetic intermediates that are not explicitly indicated in the main manuscript, and appear only in the supporting information.

\section{Synthesis and physical data for new compounds}

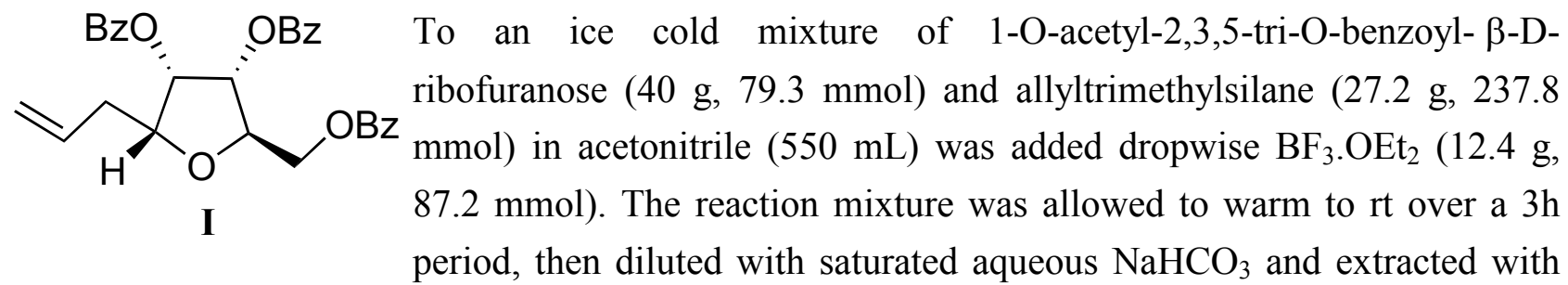

ether. The organic extract was dried $\left(\mathrm{Na}_{2} \mathrm{SO}_{4}\right)$ and concentrated under reduced pressure. The oily residue was chromatographed on silica gel (15\% EtOAc - petroleum ether) to afford $\mathbf{I}^{\mathbf{1}}(29.0 \mathrm{~g}$, $75 \%)$ and the undesired $\beta$-isomer (4.0 g, 10\%). ${ }^{1} \mathrm{H}$ NMR $\left(500 \mathrm{MHz}, \mathrm{CDCl}_{3}\right) \delta 8.09-8.05$ (dt, $J=$ 1.0, $7.9 \mathrm{~Hz}, 4 \mathrm{H}), 7.87(\mathrm{dd}, J=1.0,8.2 \mathrm{~Hz}, 2 \mathrm{H}), 7.61(\mathrm{t}, J=7.4 \mathrm{~Hz}, 1 \mathrm{H}), 7.56(\mathrm{t}, J=7.4 \mathrm{~Hz}, 1 \mathrm{H})$, 
7.50 (t, $J=7.4 \mathrm{~Hz}, 1 \mathrm{H}), 7.45(\mathrm{t}, J=7.8 \mathrm{~Hz}, 2 \mathrm{H}), 7.40(\mathrm{t}, J=7.8 \mathrm{~Hz}, 2 \mathrm{H}), 7.29(\mathrm{t}, J=7.7 \mathrm{~Hz}, 2 \mathrm{H})$, $5.94(\mathrm{dd}, J=3.90,4.6 \mathrm{~Hz}, 1 \mathrm{H}), 5.84(\mathrm{~m}, 2 \mathrm{H}), 5.17-5.10(\mathrm{~m}, 2 \mathrm{H}), 4.69(\mathrm{~m}, 2 \mathrm{H}), 4.60(\mathrm{~m}, 1 \mathrm{H}), 4.53$ $(\mathrm{dt}, J=3.60,6.9 \mathrm{~Hz}, 1 \mathrm{H}), 2.66-2.57(\mathrm{~m}, 2 \mathrm{H}) ;{ }^{13} \mathrm{C} \mathrm{NMR}\left(125 \mathrm{MHz}, \mathrm{CDCl}_{3}\right) \delta 166.4,165.6,165.5$, 133.6, 133.5, 133.3, 133.2, 129.9, 129.8, 129.6, 129.2, 128.7, 128.5, 128.4, 118.1, 79.6, 77.8, 73.8, $73.2,64.7,34.4$.

$\mathrm{NaOMe}(4.3 \mathrm{~g}, 78.9 \mathrm{mmol})$ was added to a stirred solution of tribenzoate $\mathrm{I}$
$\begin{aligned} & \text { (9.62 } \mathrm{g}, 19.7 \mathrm{mmol}) \text { in methanol }(66 \mathrm{~mL}) \text { under } \mathrm{N}_{2} \text {. The reaction mixture } \\ & \text { was stirred for } 30 \mathrm{~min} \text {, then cooled to } 0^{\circ} \mathrm{C} \text { and carefully neutralized with a } \\ & \text { under reduced pressure and chromatographed on silica gel with EtOAc as }\end{aligned}$ eluent to afford triol 12 (3.37 g, 98\%). ${ }^{1} \mathrm{H}$ NMR (500 MHz, $\left.\mathrm{CDCl}_{3}\right) \delta$ 5.88-5.83 (m, 1H), 5.22-5.11 $(\mathrm{m}, 2 \mathrm{H}), 4.28(\mathrm{dt}, J=4.7,7.7 \mathrm{~Hz}, 1 \mathrm{H}), 4.14(\mathrm{dd}, J=3.6,7.6 \mathrm{~Hz}, 1 \mathrm{H}), 4.06(\mathrm{dt}, J=3.2,7.2 \mathrm{~Hz}, 1 \mathrm{H})$, 3.90-3.86 (ovrlp m, 2H), 3.70 (m, 1H), 2.67 (d, $J=7.9 \mathrm{~Hz}, 1 \mathrm{H}$ ), 2.51-2.48 (ovrlp m, 3H), 2.03 (m, $1 \mathrm{H}) ;{ }^{13} \mathrm{C}$ NMR $\left(125 \mathrm{MHz}, \mathrm{CDCl}_{3}\right) \delta 134.4,117.8,81.5,80.7,72.9,72.7,62.5,34.3$.

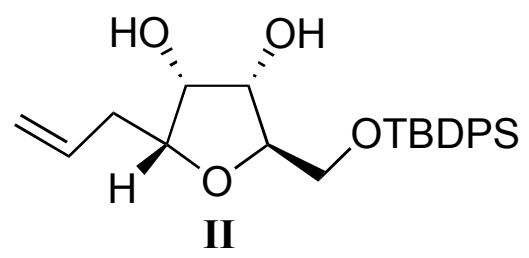

To a solution of triol $12(7.20 \mathrm{~g}, 41.4 \mathrm{mmol})$ in $\mathrm{CH}_{2} \mathrm{Cl}_{2}(200 \mathrm{~mL})$ at $0{ }^{\circ} \mathrm{C}$ was added sequentially imidazole $(4.22 \mathrm{~g}, 62.1 \mathrm{mmol})$ and TBDPSCl (11.3 g, $41.4 \mathrm{mmol})$. The resulting mixture was stirred at $0{ }^{\circ} \mathrm{C}$ for $2 \mathrm{~h}$, then treated with saturated aqueous $\mathrm{NH}_{4} \mathrm{Cl}$ and extracted with EtOAc. The organic extract was washed with brine, dried $\left(\mathrm{Na}_{2} \mathrm{SO}_{4}\right)$, filtered and concentrated under reduced pressure. Purification by chromatography (silica gel, 20\% EtOAc - petroleum ether) afforded diol II (14.9 g, 88\%) as a colorless oil. ${ }^{1} \mathrm{H}$ NMR $\left(500 \mathrm{MHz}, \mathrm{CDCl}_{3}\right)$ 8 7.74-7.70 (m, 4H), 7.43-7.29 (m, 6H), 5.90-5.88 (m, 1H), 5.23-5.12 (m, 2H), $4.46(\mathrm{dt}, J=4.8,6.8 \mathrm{~Hz}, 1 \mathrm{H}), 4.15-4.11(\mathrm{~m}, 1 \mathrm{H}), 4.10-4.07(\mathrm{dt}, J=3.0,7.1 \mathrm{~Hz}, 1 \mathrm{H}), 3.94-3.91(\mathrm{~m}$, $1 \mathrm{H}), 3.85(\mathrm{~d}, J=4.0 \mathrm{~Hz}, 2 \mathrm{H}), 2.61(\mathrm{~m}, 1 \mathrm{H}), 2.57(\mathrm{~m}, 1 \mathrm{H}), 2.48(\mathrm{t}, J=7.0 \mathrm{~Hz}, 2 \mathrm{H}), 1.08(\mathrm{~s}, 9 \mathrm{H}) ;{ }^{13} \mathrm{C}$ NMR (125 MHz, $\left.\mathrm{CDCl}_{3}\right) \delta 135.8,134.7,133.4,133.3,130.0,128.0,117.4,81.9,80.9,74.3,73.0$, 64.7, 34.2, 27.1, 19.4; ESIHRMS (M+Na) ${ }^{+}$calculated for $\mathrm{C}_{24} \mathrm{H}_{32} \mathrm{O}_{4} \mathrm{Na} 435.1962$, found 435.1947.

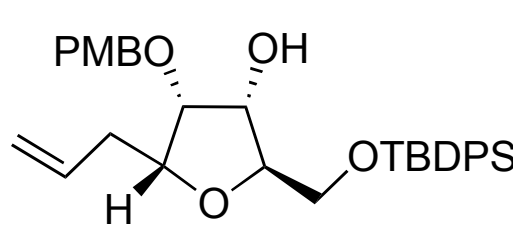

13

To a solution of diol II ( $3.30 \mathrm{~g}, 8.08 \mathrm{mmol})$ in anhydrous benzene $(50 \mathrm{~mL})$ was added sequentially $p$-anisaldehyde $(1.96 \mathrm{~mL}, 16.17$ heated at reflux for $1 \mathrm{~h}$, cooled to rt quenched with $\mathrm{NaHCO}_{3}$ and extracted with ether. The organic extract was dried $\left(\mathrm{Na}_{2} \mathrm{SO}_{4}\right)$ and concentrated under reduced pressure. Purification by chromatography (silica gel, 5\% EtOAc -

\footnotetext{
${ }^{1}$ A. P.; Sorgi, K. L.; Wang, B. C.; Xu, Z. B. Tetrahedron Lett. 1983, 24, 1563-1566.
} 
petroleum ether) afforded a mixture of the benzylidene derivatives of II ( $3.85 \mathrm{~g}, 87 \%)$ as a colorless oil. ${ }^{1} \mathrm{H}$ NMR (500 MHz, $\left.\mathrm{CDCl}_{3}\right) \delta$ 7.68-7.66 (m, 4H), 7.44-7.41 (m, 8H), 6.94-6.92 (d, $J=8.3 \mathrm{~Hz}$, 2H), 5.93-5.82 (ovrlp m, 2H), 5.11-4.95 (ovrlp m, 3H), 4.78 (m, 1H), 4.31-4.28 (ovrlp m, 2H), 3.833.78 (ovrlp m, 5H), 2.57-2.51(m, 2H), 1.08 (s, 9H); ${ }^{13} \mathrm{C} \mathrm{NMR} \mathrm{(125} \mathrm{MHz,} \mathrm{CDCl}_{3}$ ) $\delta$ 161.0, 160.8, $135.8,135.0,134.8,133.1,133.0,130.1,129.1,128.9,128.8,128.4,128.0,117.3,117.1,114.0$, $106.3,104.8,84.7,84.2,84.0,83.1,82.9,82.6,82.0,81.9,77.0,65.5,65.4,55.6,55.5,34.3,27.2$, 27.0, 19.3.

A solution of the product from the previous step $(2.66 \mathrm{~g}, 5.0 \mathrm{mmol})$ in anhydrous $\mathrm{CH}_{2} \mathrm{Cl}_{2}(30 \mathrm{~mL})$ was purged with argon and cooled to $-78^{\circ} \mathrm{C}$. DIBAL-H $(11.5 \mathrm{~mL}$ of a $1.0 \mathrm{M}$ solution in toluene, 11.5 mmol) was added dropwise and the reaction mixture was slowly warmed to $0{ }^{\circ} \mathrm{C}$. The resulting mixture was stirred at $0{ }^{\circ} \mathrm{C}$ for $3 \mathrm{~h}$, then treated with saturated aqueous Rochelle salt and stirred for $1 \mathrm{~h}$ at $\mathrm{rt}$. The mixture was extracted with EtOAc $(4 \times 30 \mathrm{~mL})$, washed with brine, dried $\left(\mathrm{Na}_{2} \mathrm{SO}_{4}\right)$, filtered, and concentrated under reduced pressure. Purification by chromatography (silica gel, $20 \%$ EtOAc - petroleum ether) afforded $13(1.4 \mathrm{~g}, 53 \%)$ and the desilylated derivative (487 $\mathrm{mg}, 33 \%)$. For 13: colorless oil; $[\alpha]_{\mathrm{D}}{ }^{24}-7.6\left(c 1.0, \mathrm{CHCl}_{3}\right) ;{ }^{1} \mathrm{H} \mathrm{NMR}\left(500 \mathrm{MHz}, \mathrm{CDCl}_{3}\right) \delta$ 7.73-7.69 (m, 4H), 7.46-7.38 (m, 6H), 7.33-7.31 (d, $J=8.3 \mathrm{~Hz}, 2 \mathrm{H}), 6.93(\mathrm{~d}, J=8.3 \mathrm{~Hz}, 2 \mathrm{H}), 5.93-5.88$ (m, 1H), 5.19$5.11(\mathrm{~m}, 2 \mathrm{H}), 4.70-4.68(\mathrm{~d}, J=11.2 \mathrm{~Hz}, 1 \mathrm{H}), 4.62-4.60(\mathrm{~d}, J=11.2 \mathrm{~Hz}, 1 \mathrm{H}), 4.45-4.41(\mathrm{~m}, 1 \mathrm{H})$, 4.20-4.16 (m, 1H), 4.07 (t, $J=4.5 \mathrm{~Hz}, 1 \mathrm{H}), 3.91(\mathrm{~m}, 1 \mathrm{H}), 3.86-3.83$ ( ovrlp m, 4H), 3.79-3.76 (dd, $J$ $=2.7,11.1 \mathrm{~Hz}, 1 \mathrm{H}), 2.56-2.43$ (ovrlp m, 3H), $1.06(\mathrm{~s}, 9 \mathrm{H}) ;{ }^{13} \mathrm{C} \mathrm{NMR}\left(125 \mathrm{MHz}, \mathrm{CDCl}_{3}\right) \delta 159.8$, 136.1, 136.0, 135.9, 135.8, 135.5, 133.6, 133.5, 130.0, 129.9, 129.8, 128.1, 128.0, 127.9, 116.9, 114.2, 83.6, 80.4, 80.3, 74.2, 72.9, 64.6, 55.5, 35.0, 27.0, 19.4; ESIHRMS $(\mathrm{M}+\mathrm{Na})^{+}$calculated for $\mathrm{C}_{32} \mathrm{H}_{40} \mathrm{O}_{5} \mathrm{NaSi} 555.2529$, found 555.2531. For desilylated product: white solid; ${ }^{1} \mathrm{H}$ NMR (500 $\left.\mathrm{MHz}, \mathrm{CDCl}_{3}\right) \delta 7.33-7.31(\mathrm{~d}, J=8.3 \mathrm{~Hz}, 2 \mathrm{H}), 6.93(\mathrm{~d}, J=8.3 \mathrm{~Hz}, 2 \mathrm{H}), 5.89-5.84(\mathrm{~m}, 1 \mathrm{H}), 5.18-$ $5.11(\mathrm{~m}, 2 \mathrm{H}), 4.70-4.68(\mathrm{~d}, J=11.2 \mathrm{~Hz}, 1 \mathrm{H}), 4.62-4.60(\mathrm{~d}, J=11.2 \mathrm{~Hz}, 1 \mathrm{H}), 4.19(\mathrm{~m}, 1 \mathrm{H}), 4.14-4.12$ (m, 1H), 4.00-3.98 (t, $J=4.7 \mathrm{~Hz}, 1 \mathrm{H}$ ), 3.87-3.83 (ovrlp m, 5H), 3.67 (m, 1H), 2.54-2.46 (ovrlp m, $3 \mathrm{H}), 1.95(\mathrm{br}, 1 \mathrm{H})$. Reprotection of desilylated product with TBDPSCl reagent led to intermediate 13 with $85 \%$ combined yield.

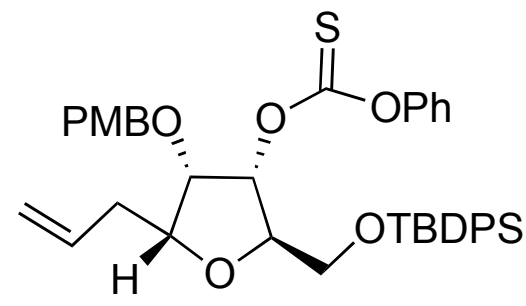

III
To a solution of alcohol $\mathbf{1 3}(8.9 \mathrm{~g}, 16.73 \mathrm{mmol})$ in anhydrous toluene $(60 \mathrm{~mL})$ was added pyridine $(4.10 \mathrm{~mL}, 50.2 \mathrm{mmol})$. The reaction mixture was cooled to $0{ }^{\circ} \mathrm{C}$ and phonoxythionocarbanate (4.53 mL, $33.5 \mathrm{mmol})$ was added dropwise. The mixture was 
warmed to rt, stirred for $12 \mathrm{~h}$ at this temperature, then quenched with saturated aqueous $\mathrm{NH}_{4} \mathrm{Cl}$ solution. After stirring for an additional $0.5 \mathrm{~h}$, the mixture extracted with $\mathrm{Et}_{2} \mathrm{O}(3 \mathrm{x} 60 \mathrm{~mL})$, washed with brine, dried $\left(\mathrm{Na}_{2} \mathrm{SO}_{4}\right)$, filtered, and concentrated under reduced pressure. Purification by chromatography (silica gel, 5\% EtOAc - petroleum ether) afforded thioester III (10.2 g, 90\%) as a light yellow oil . ${ }^{1} \mathrm{H}$ NMR $\left(500 \mathrm{MHz}, \mathrm{CDCl}_{3}\right) \delta$ 7.72-7.69 (m, 4H), 7.45-7.37 (m, 8H), 7.33-7.29 $(\mathrm{m}, 3 \mathrm{H}), 7.04(\mathrm{~d}, J=8.4 \mathrm{~Hz}, 2 \mathrm{H}), 6.90(\mathrm{~d}, J=8.5 \mathrm{~Hz}, 2 \mathrm{H}), 5.96(\mathrm{t}, J=5.0 \mathrm{~Hz}, 1 \mathrm{H}), 5.88-5.80(\mathrm{~m}$, $1 \mathrm{H}), 5.14-5.08(\mathrm{~m}, 2 \mathrm{H}), 4.68(\mathrm{~d}, J=11.2 \mathrm{~Hz}, 1 \mathrm{H}), 4.54(\mathrm{~d}, J=11.2 \mathrm{~Hz}, 1 \mathrm{H}), 4.43(\mathrm{t}, J=4.9 \mathrm{~Hz}, 1 \mathrm{H})$, $4.33(\mathrm{~m}, 1 \mathrm{H}), 4.23(\mathrm{~m}, 1 \mathrm{H}), 3.85-3.82$ (ovrlp m, 5H), $2.44(\mathrm{t}, J=7.0 \mathrm{~Hz}, 2 \mathrm{H}), 1.07(\mathrm{~s}, 9 \mathrm{H}) ;{ }^{13} \mathrm{C} \mathrm{NMR}$ $\left(125 \mathrm{MHz} \mathrm{CDCl}_{3}\right) \delta 194.6,159.4,153.6,153.4,135.7,135.1,133.1,130.0,129.9,129.8,129.7$, 129.6, 129.5, 127.8, 127.7, 126.8, 126.6, 121.9, 121.8, 116.8, 113.9, 83.0, 80.2, 77.5, 73.6, 64.1, 55.3, 34.3, 26.8, 19.2; ESIHRMS $(\mathrm{M}+\mathrm{Na})^{+}$calculated for $\mathrm{C}_{39} \mathrm{H}_{44} \mathrm{O}_{6} \mathrm{NaSiS}$ 691.2520, found 691.2512.

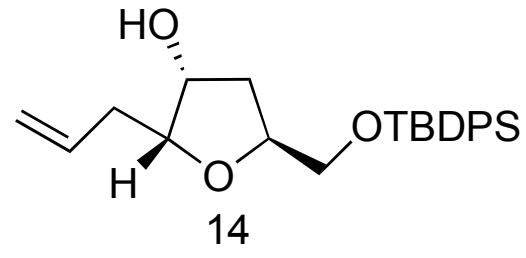

To a solution of thioester III (400 $\mathrm{mg}, 0.63 \mathrm{mmol})$ in anhydrous benzene $(4.3 \mathrm{~mL})$ was added $\mathrm{Bu}_{3} \mathrm{SnH}(0.34 \mathrm{~mL}, 1.26 \mathrm{mmol})$ and AIBN (10.4 mg, $0.063 \mathrm{mmol})$. The solution was degassed twice and heated at reflux for $4 \mathrm{~h}$. After evaporation of the solvent, the crude residue was dissolved in a mixture of $\mathrm{CH}_{2} \mathrm{Cl}_{2}(5.0 \mathrm{~mL}), \mathrm{pH} 7$ buffer (0.7 mL solution of a $1 \mathrm{M}$ solution of $\mathrm{NaH}_{2} \mathrm{PO}_{4} / \mathrm{Na}_{2} \mathrm{HPO}_{4}$ buffer) and cooled to $0{ }^{\circ} \mathrm{C}$. DDQ (215 $\mathrm{mg}, 0.95 \mathrm{mmol}$ ) was added in one portion and after $10 \mathrm{~min}$, the reaction mixture was warmed to $\mathrm{rt}$, stirred for $2 \mathrm{~h}$ at this temperature. The mixture was then quenched with saturated aqueous $\mathrm{NaHCO}_{3}$, extracted with EtOAc, washed with brine, dried $\left(\mathrm{Na}_{2} \mathrm{SO}_{4}\right)$ and concentrated in vacuo. Purification by chromatography (silica gel, 15\% EtOAc - petroleum ether) afforded alcohol 14 (160 mg, 60\%) as a colorless oil. $[\alpha]_{\mathrm{D}}{ }^{24}-1.2\left(\mathrm{c} 0.3, \mathrm{CHCl}_{3}\right) ;{ }^{1} \mathrm{H} \mathrm{NMR}\left(500 \mathrm{MHz}, \mathrm{CDCl}_{3}\right) \delta$ 7.72-7.68 (m, 4H), 7.407.39 (m, 6H), 5.94-5.86 (m, 1H), 5.22-5. FTIR (neat) 3427, 3072, 3048, 2932, 2856, 1644, 1589, 1472, $1425,1107 \mathrm{~cm}^{-1}$; 0 (m, 2H), 4.39-4.35 (m, 1H), 4.32-4.29 ( m, 1H), 3.95-3.92 (dt, J= 2.8, 7.1 Hz, $1 \mathrm{H}), 3.77$ (dd, $J=4.2,10.8 \mathrm{~Hz}, 1 \mathrm{H}), 3.65$ (dd, $J=4.1,10.8 \mathrm{~Hz}, 1 \mathrm{H}), 2.50-2.43$ (m, 2H) , 2.21-2.19 $(\mathrm{m}, 1 \mathrm{H}), 2.08-2.05(\mathrm{dd}, J=6.8,13.4 \mathrm{~Hz}, 1 \mathrm{H}), 1.59(\mathrm{~d}, J=6.1 \mathrm{~Hz}, 1 \mathrm{H}), 1.06(\mathrm{~s}, 9 \mathrm{H}) ;{ }^{13} \mathrm{C}$ NMR $(125$ $\left.\mathrm{MHz}, \mathrm{CDCl}_{3}\right) \delta 135.9,135.1,133.7,129.9,127.9,117.2,88.2,77.6,73.7,66.4,37.3,34.1,27.0$, 19.5; ESIHRMS (M+Na) ${ }^{+}$calculated for $\mathrm{C}_{24} \mathrm{H}_{32} \mathrm{O}_{3} \mathrm{NaSi} 419.2012$, found 419.2010.

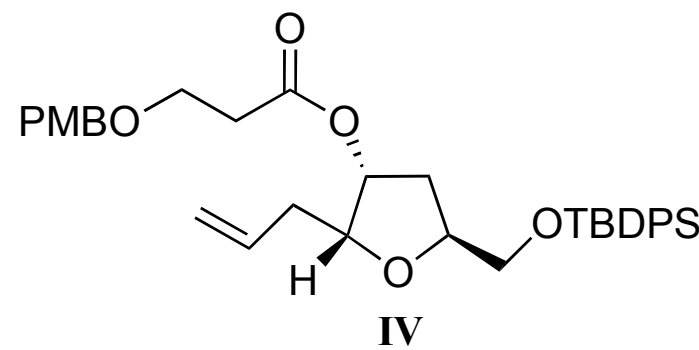

A mixture of alcohol $14(1.2 \mathrm{~g}, 3.03 \mathrm{mmol})$ and $3-\mathrm{p}$ methoxybenzoxy propionic (827 $\mathrm{mg}, 3.94 \mathrm{mmol}$ ) was dried by removal of the benzene-water azeotrope. The residual benzene solution $(10 \mathrm{~mL})$ was cooled to $\mathrm{rt}$, DMAP (74 mg, $0.61 \mathrm{mmol}$ ) added in one portion, the 
mixture cooled to $0{ }^{\circ} \mathrm{C}$, DCC $(813 \mathrm{mg}, 3.94 \mathrm{mmol})$ was then added and the reaction warmed to rt and stirred for $2 \mathrm{~h}$. Ether was next added, the resulting suspension, filtered and the filtrate concentrated in vacuo. Purification by chromatography (silica gel, 5\% EtOAc -petroleum ether) afforded ester IV (1.6 g, 90\%) as a colorless oil. FTIR (neat) 3072, 2932, 2859, 1735, 1612, 1513, 1472, 1425, 1248, $1178 \mathrm{~cm}^{-1}$; ${ }^{1} \mathrm{H}$ NMR $\left(500 \mathrm{MHz}, \mathrm{CDCl}_{3}\right) \delta$ 7.76-7.71 (m, 4H), 7.45-7.42 (m, $6 \mathrm{H}), 7.29(\mathrm{~d}, J=8.7 \mathrm{~Hz}, 2 \mathrm{H}), 6.90(\mathrm{~d}, J=8.7 \mathrm{~Hz}, 2 \mathrm{H}), 5.89-5.82(\mathrm{~m}, 1 \mathrm{H}), 5.44(\mathrm{t}, J=3.9 \mathrm{~Hz}, 1 \mathrm{H})$, 5.18-5.09 (m, 2H), 4.53-4.48 (d, $J=11.6 \mathrm{~Hz}, 2 \mathrm{H}), 4.36-4.33(\mathrm{~m}, 1 \mathrm{H}), 4.14-4.10(\mathrm{~m}, 1 \mathrm{H}), 3.84-3.78$ (ovrlp m, 6H), 3.68-3.65 (dd, $J=3.8,10.9 \mathrm{~Hz}, 1 \mathrm{H}$ ), 2.70-2.67 (t, $J=6.3 \mathrm{~Hz}, 2 \mathrm{H}$ ), 2.47-2.33 (ovrlp $\mathrm{m}, 3 \mathrm{H}), 2.12-2.08(\mathrm{~m}, 1 \mathrm{H}), 1.10(\mathrm{~s}, 9 \mathrm{H}) ;{ }^{13} \mathrm{C} \mathrm{NMR}\left(125 \mathrm{MHz}, \mathrm{CDCl}_{3}\right) \delta 171.2,159.3,135.7,134.6$, 133.5, 130.1, 129.7, 129.3, 127.7, 117.0, 113.8, 81.0, 77.7, 75.7, 72.8, 66.0, 65.4, 55.3, 35.4, 34.9, 34.1, 26.9, 19.3; ESIHRMS (M+Na) ${ }^{+}$calculated for $\mathrm{C}_{35} \mathrm{H}_{44} \mathrm{O}_{6} \mathrm{NaSi} 611.2799$, found 611.2796.

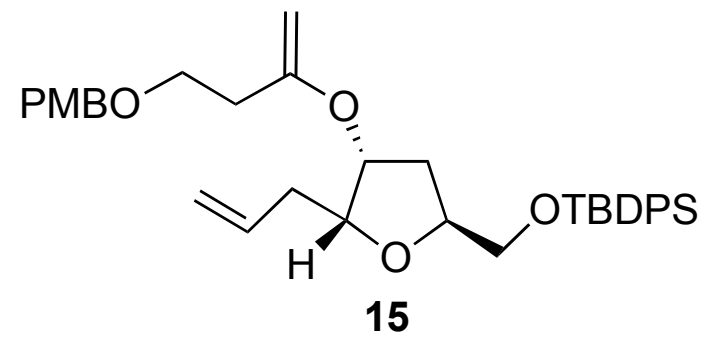

TMEDA (2.60 mL, $17.3 \mathrm{mmol})$ was added in one portion to an ice-cold mixture of $\mathrm{TiCl}_{4}(13.3 \mathrm{~mL}$ of a $1 \mathrm{M}$ solution in $\left.\mathrm{CH}_{2} \mathrm{Cl}_{2}, 13.3 \mathrm{mmol}\right)$ and THF $(15 \mathrm{~mL})$. The resulting yellow-brown suspension was allowed to warm to $\mathrm{rt}$ and stirred for an additional $30 \mathrm{~min}$ at this temperature. Zinc dust (1.25 g, $19.3 \mathrm{mmol})$ and $\mathrm{PbCl}_{2}(14 \mathrm{mg}, 0.05 \mathrm{mmol})$ were added sequentially and the mixture stirred for $10 \mathrm{~min}$. To the resulting suspension, was added in one portion, a mixture of ester IV $(500 \mathrm{mg}, 0.85 \mathrm{mmol})$ and $\mathrm{CH}_{2} \mathrm{Br}_{2}(0.76 \mathrm{~mL}, 10.9 \mathrm{mmol})$ in THF $(7 \mathrm{~mL})$. The reaction mixture was stirred at the $\mathrm{rt}$ for $1 \mathrm{~h}$, cooled to $0{ }^{\circ} \mathrm{C}$ and quenched by the dropwise addition of saturated aqueous $\mathrm{K}_{2} \mathrm{CO}_{3}(1.0 \mathrm{~mL})$. The mixture was stirred at the $\mathrm{rt}$ for 30 min., diluted with ether and filtered through neutral alumina using 3\% triethylamine - ether as the eluent. The eluate was concentrated and purification of the residue purified by chromatography (neutral alumina, 2\% EtOAc - petroleum ether containing 2\% triethylamine) afforded compound 15 (370 mg, $74 \%$ ) as a colorless oil. ${ }^{1} \mathrm{H}$ NMR (500 MHz, $\left.\mathrm{C}_{6} \mathrm{D}_{6}\right) \delta$ 7.86-7.81 (m, 4H), 7.27-7.22 (ovrlp $\mathrm{m}, 8 \mathrm{H}), 6.79(\mathrm{~d}, J=8.6 \mathrm{~Hz}, 2 \mathrm{H}), 6.01-5.93(\mathrm{~m}, 1 \mathrm{H}), 5.18-5.06(\mathrm{~m}, 2 \mathrm{H}), 4.34-4.32(\mathrm{~d}, J=8.3 \mathrm{~Hz}$, $2 \mathrm{H}), 4.27-4.24(\mathrm{~m}, 2 \mathrm{H}), 4.05(\mathrm{~d}, J=1.8 \mathrm{~Hz}, 1 \mathrm{H}), 3.97(\mathrm{~m}, 1 \mathrm{H}), 3.85(\mathrm{~d}, J=1.9 \mathrm{~Hz}, 1 \mathrm{H}), 3.73-3.70$ (dd, $J=3.6,10.8 \mathrm{~Hz}, 1 \mathrm{H}), 3.60-3.58(\mathrm{t}, J=6.7 \mathrm{~Hz}, 2 \mathrm{H}), 3.52-3.49$ (dd, $J=4.4,10.9 \mathrm{~Hz}, 1 \mathrm{H}), 3.30$ (s, 3H), 2.67-2.62 (m, 1H), 2.53-2.45 (ovrlp m, 3H), 2.08-2.04 ( m, 1H), 1.82-1.77 (m, 1H), $1.18(\mathrm{~s}$, 9H); ${ }^{13} \mathrm{C}$ NMR $\left(125 \mathrm{MHz}, \mathrm{C}_{6} \mathrm{D}_{6}\right) \delta 160.0,159.3,136.5,136.3,134.4,131.6,130.4,130.3,129.7$, $128.9,128.7,128.6,128.5,128.4,128.3,128.2,117.1,114.4,84.0,82.1,78.4,77.9,73.0,68.3$, 67.0, 55.1, 36.8, 34.9, 33.9, 27.4, 19.9; ESIHRMS $(\mathrm{M}+\mathrm{Na})^{+}$calculated for $\mathrm{C}_{36} \mathrm{H}_{46} \mathrm{O}_{5} \mathrm{NaSi}$ 609.3006, found 609.3003. 


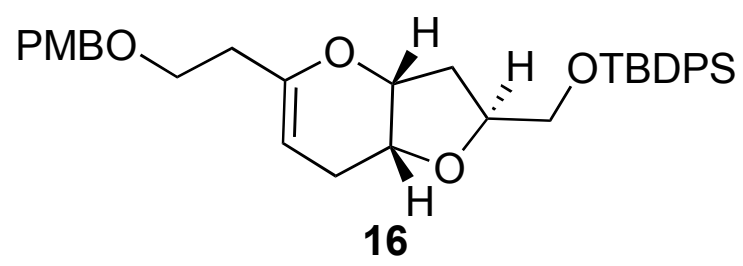

To a solution of enol ether 15 (400 $\mathrm{mg}, 0.68 \mathrm{mmol})$ and $\mathrm{CH}_{2} \mathrm{Cl}_{2}(68 \mathrm{~mL})$ was added Grubbs II catalyst $(57 \mathrm{mg}$, $0.06 \mathrm{mmol}$ ), the mixture was heated at reflux for $12 \mathrm{~h}$, cooled to $\mathrm{rt}$ and quenched by addition of anhydrous DMSO $(1.0 \mathrm{~mL})$. The mixture was stirred at $50{ }^{\circ} \mathrm{C}$ for

$2 \mathrm{~h}$, concentrated under reduced pressure and the residue purified by chromatography (neutral alumina, 10\% EtOAc - petroleum ether containing 1\% triethylamine) to give glycal 16 (266 mg, 70 $\%)$ as a colorless oil. ${ }^{1} \mathrm{H}$ NMR $\left(500 \mathrm{MHz}, \mathrm{CDCl}_{3}\right) \delta$ 7.75-7.70 (m, 4H), 7.41-7.40 (m, 6H), 7.30$7.28(\mathrm{~d}, J=8.6 \mathrm{~Hz}, 2 \mathrm{H}), 6.79$ ( d, $J=9.4 \mathrm{~Hz}, 2 \mathrm{H}), 4.53(\mathrm{~m}, 1 \mathrm{H}), 4.48(\mathrm{~d}, J=11.8 \mathrm{~Hz}, 2 \mathrm{H}), 4.36(\mathrm{~m}$, $1 \mathrm{H}), 4.33(\mathrm{~m}, 1 \mathrm{H}), 4.20(\mathrm{~m}, 1 \mathrm{H}), 3.86-3.82$ (ovrlp m, 4H), 3.71-3.68 (dd, $J=3.8,10.8 \mathrm{~Hz}, 1 \mathrm{H})$, 3.63-3.58 (m, 2H), 2.38-2.36 (t, $J=6.9 \mathrm{~Hz}, 2 \mathrm{H}), 2.34-2.25(\mathrm{~m}, 2 \mathrm{H}), 2.24-2.19(\mathrm{~m}, 2 \mathrm{H}), 1.09$ (s, 9H); ${ }^{13} \mathrm{C}$ NMR $\left(125 \mathrm{MHz}, \mathrm{CDCl}_{3}\right) \delta 159.1,150.1,135.7,135.6,133.6,130.6,129.7,129.6,129.3$, $127.7,113.8,92.6,77.8,75.8,74.7,72.5,67.5,66.0,55.3,36.1,34.9,26.9,23.2,19.3$; ESIHRMS $(\mathrm{M}+\mathrm{Na})^{+}$calculated for $\mathrm{C}_{34} \mathrm{H}_{42} \mathrm{O}_{5} \mathrm{NaSi}$ 581.2693, found 581.2692.

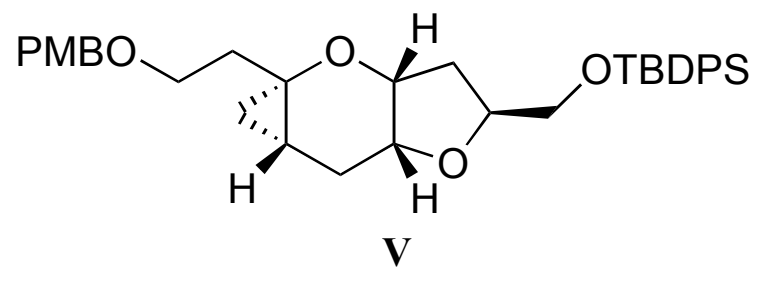

To a mixture of enol ether $\mathbf{1 6}(100 \mathrm{mg}, 0.18 \mathrm{mmol})$ and diethyl zinc $(0.90 \mathrm{~mL}, 0.90 \mathrm{mmol})$ in anhydrous toluene $(3 \mathrm{~mL})$ was added diiodomethane $(1.14 \mathrm{~mL}$, $1.78 \mathrm{mmol})$. The reaction stirred at $\mathrm{rt}$ for $2 \mathrm{~h}$ then diluted with saturated aqueous $\mathrm{NH}_{4} \mathrm{Cl}$. The mixture was extracted with ether and the combined organic solvent washed with brine, dried $\left(\mathrm{Na}_{2} \mathrm{SO}_{4}\right)$ and concentrated under reduced pressure. The residue was purified by chromatography (silica gel, 10\% EtOAc - petroleum ether ) to provide cyclopropane $\mathbf{V}(83 \mathrm{mg}, 80 \%)$ as a colorless oil. ${ }^{1} \mathrm{H}$ NMR (500 $\left.\mathrm{MHz}, \mathrm{CDCl}_{3}\right)$ d 7.70-7.67 (m, 4H), 7.46-7.38 (m, 6H), 7.30-7.28 (m, 2H), 6.91-6.89 ( $\left.\mathrm{m}, 2 \mathrm{H}\right), 4.48$ (s, 2H), 4.34-4.32 (m, 1H), 4.21-4.17 ( m, 1H), 4.15-4.11 (m, 1H), 3.83 (s, 3H), 3.75-3.70 (m, 1H), 3.70-3.64 (m, 3H), 2.45-2.42 (m, 1H), 2.29-2.27 (m, 1H), 2.07-2.02( m, 1H), 1.95-1.91 (m, $1 \mathrm{H})$, 1.49-1.43 (m, 1H), 1.22-1.18 (m, 1H), 1.07 (s, 9H), 0.78-0.73 (m, 2H), 0.64-0.62 (dd, $J=3.6$, $4.5 \mathrm{~Hz}, 1 \mathrm{H}) ;{ }^{13} \mathrm{C}$ NMR $\left(125 \mathrm{MHz}, \mathrm{CDCl}_{3}\right) \delta 159.2,135.6,134.8,133.5,130.6,129.7,129.6,129.3$, $127.7,113.8,92.6,77.1,74.8,72.8,67.7,66.3,57.0,55.3,35.6,33.8,27.6,26.9,20.8,19.2,14.3$.

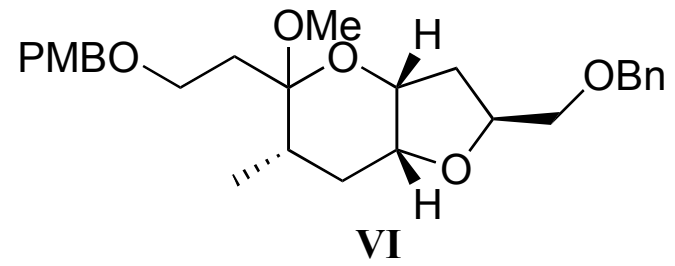

To a solution of cyclopropane $\mathbf{V}(28 \mathrm{mg}, 0.05 \mathrm{mmol})$ in anhydrous $\mathrm{MeOH}(1 \mathrm{~mL})$ was added IDCP $(55.0 \mathrm{mg}, 0.12$ $\mathrm{mmol}$ ) in one portion. The reaction mixture was stirred at $\mathrm{rt}$ for $1 \mathrm{~h}$ then quenched with saturated aqueous $\mathrm{Na}_{2} \mathrm{~S}_{2} \mathrm{O}_{3}$ and extracted with ether. The organic extract was washed with 
brine, dried $\left(\mathrm{Na}_{2} \mathrm{SO}_{4}\right)$, concentrated under reduced pressure and the crude product was dried by distillation of the benzene-water azeotrope ( 3 times). The residue was dissolved in dry toluene ( 1 $\mathrm{mL})$, AIBN (1.5 mg, $0.01 \mathrm{mmol})$ and $\mathrm{Bu}_{3} \mathrm{SnH}(0.03 \mathrm{~mL}, 0.09 \mathrm{mmol})$ were added sequentially. The reaction mixture was heated at reflux for $2 \mathrm{~h}$ then concentrated in vacuo. The residue was purified by chromatography (silica gel, 15\% EtOAc - petroleum ether) to afford compound VI (24 mg, 80\%). ${ }^{1} \mathrm{H}$ NMR $\left(500 \mathrm{MHz}, \mathrm{CDCl}_{3}\right) \delta$ 7.72-7.68 (m, 4H), 7.41-7.39 (m, 6H), $7.27(\mathrm{~m}, 2 \mathrm{H}), 6.89(\mathrm{~m}, 2 \mathrm{H})$, $4.46(\mathrm{~d}, J=11.6 \mathrm{~Hz}, 2 \mathrm{H}), 4.34-4.30(\mathrm{~m}, 1 \mathrm{H}), 4.12(\mathrm{~m}, 1 \mathrm{H}), 3.96-3.94(\mathrm{~m}, 1 \mathrm{H}), 3.83(\mathrm{~s}, 3 \mathrm{H}), 3.77-$ 3.74 (dd, $J=4.7,10.6 \mathrm{~Hz}, 1 \mathrm{H}), 3.73-3.70$ ( dd, $J=4.0,10.6 \mathrm{~Hz}, 1 \mathrm{H}), 3.50-3.46$ (m, 2H), 3.25 (s, $3 \mathrm{H}), 2.17-2.13(\mathrm{~m}, 1 \mathrm{H}), 2.10-2.03(\mathrm{~m}, 2 \mathrm{H}), 2.00-1.97(\mathrm{~m}, 1 \mathrm{H}), 1.74-1.70(\mathrm{~m}, 1 \mathrm{H}), 1.67-1.61(\mathrm{~m}$, 2H), $1.11(\mathrm{~d}, J=7.3 \mathrm{~Hz}, 3 \mathrm{H}), 1.07$ (s, 9H); ${ }^{13} \mathrm{C}$ NMR $\left(125.0 \mathrm{MHz}, \mathrm{CDCl}_{3}\right) \delta 159.1,135.7,135.6$, 133.7, 130.5, 129.6, 129.1, 127.6, 113.8, 101.1, 77.5, 75.7, 72.7, 72.4, 66.4, 64.9, 55.3, 48.2, 35.9, $31.9,31.3,29.2,26.9,19.3,17.5$.

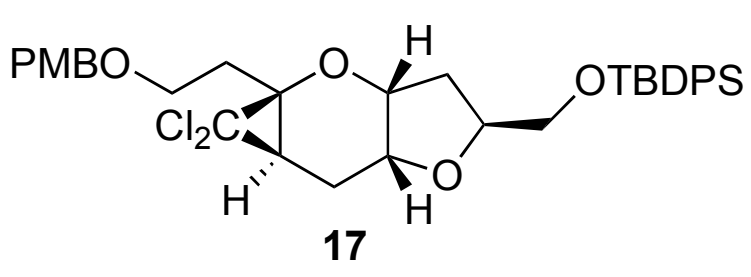

To a solution of glycal 16 (226 mg, $0.404 \mathrm{mmol})$ in vigorously for $12 \mathrm{~h}$ at $\mathrm{rt}$. The reaction was then quenched with water and the mixture extracted with $\mathrm{CH}_{2} \mathrm{Cl}_{2}$. The organic extract was washed with water, brine, dried $\left(\mathrm{Na}_{2} \mathrm{SO}_{4}\right)$, concentrated in vacuo and the residue purified by chromatography (silica gel, $5 \%$ EtOAc - petroleum ether) to afford chlorocyclopropane 17 (202 mg, 80\%) and stereoisomer (22 mg, 8\%). [ $[\alpha]_{\mathrm{D}}{ }^{24}-0.85\left(c 1.0, \mathrm{CHCl}_{3}\right)$; ${ }^{1} \mathrm{H}$ NMR $\left(500 \mathrm{MHz}, \mathrm{CDCl}_{3}\right) \delta$ 7.70-7.68 (m, 4H), 7.68-7.39 (m, 6H), $7.29(\mathrm{~d}, J=8.6 \mathrm{~Hz}, 2 \mathrm{H}), 6.89$ ( d, $J=9.4 \mathrm{~Hz}, 2 \mathrm{H}), 4.50(\mathrm{~s}, 2 \mathrm{H}), 4.29-4.25(\mathrm{~m}, 1 \mathrm{H}), 4.22(\mathrm{t}, J=3.7 \mathrm{~Hz}, 1 \mathrm{H}), 3.95-3.91(\mathrm{~m}, 1 \mathrm{H})$, 3.84-3.77 (ovrlp m, 6H), 3.61-3.58 (dd, $J=3.8,11.0 \mathrm{~Hz}, 1 \mathrm{H}$ ), 2.59-2.53 (m, 1H), 2.27-2.11( ovrlp $\mathrm{m}, 4 \mathrm{H}), 1.82-1.77(\mathrm{dt}, J=3.7,15.6 \mathrm{~Hz}, 1 \mathrm{H}), 1.59$ (dd, $J=4.2,10.3 \mathrm{~Hz}, 1 \mathrm{H}), 1.09(\mathrm{~s}, 9 \mathrm{H}) ;{ }^{13} \mathrm{C}$ NMR $\left(125 \mathrm{MHz}, \mathrm{CDCl}_{3}\right) \delta 159.4,135.8,133.6,132.4,131.1,130.8,130.0,129.7,129.5,129.4,127.9$, 114.2, 114.0, 113.7, 113.6, 78.2, 77.0, 76.1, 73.1, 72.1, 68.2, 66.4, 60.9, 55.5, 37.2, 35.6, 27.1, 26.7, 19.9, 19.5; ESIHRMS $\left(\mathrm{M}+\mathrm{NH}_{4}\right)^{+}$calculated for $\mathrm{C}_{35} \mathrm{H}_{46} \mathrm{NO}_{5} \mathrm{Si} \mathrm{Cl}_{2} 658.2516$, found 658.2498.

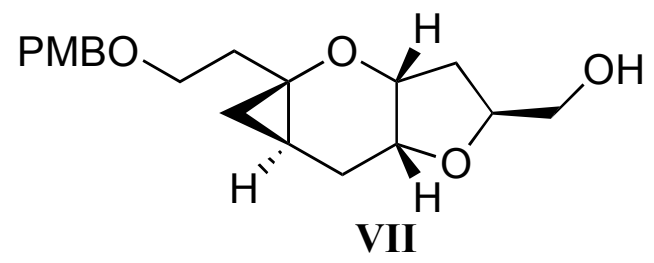

An oven-dried round-bottom flask containing compound $\mathbf{1 7}$ (132 $\mathrm{mg}, 0.205 \mathrm{mmol}$ ) was evacuated under high vacuum and purged with argon. Anhydrous THF $(2 \mathrm{~mL})$ was added, the resulting solution cooled to $0{ }^{\circ} \mathrm{C}$ and $\mathrm{LAH}$ powder $(117$ $\mathrm{mg}, 3.075 \mathrm{mmol}$ ) introduced in one portion. The suspension was stirred at $\mathrm{rt}$ for $12 \mathrm{~h}$ and quenched at $0{ }^{\circ} \mathrm{C}$ by dropwise addition of EtOAc $(2.0 \mathrm{~mL})$. The 
reaction mixture was neutralized by adding $1 \mathrm{M} \mathrm{HCl}$, then extracted with EtOAc. The organic phase was washed with water and brine, dried $\left(\mathrm{Na}_{2} \mathrm{SO}_{4}\right)$, concentrated under reduced pressure and purified by chromatography (silica gel, $30 \%$ EtOAc - petroleum ether) to give cyclopropane VII (54 mg, 79 \%). $[\alpha]_{\mathrm{D}}{ }^{24} 0.12\left(c 1.0, \mathrm{CHCl}_{3}\right) ;{ }^{1} \mathrm{H}$ NMR $\left(500 \mathrm{MHz}, \mathrm{CDCl}_{3}\right) \delta$ 7.35-7.26 (m, 2H), 6.90-6.87 ( d, $J=$ $8.6 \mathrm{~Hz}, 2 \mathrm{H}), 4.46$ (s, 2H), 4.37-4.32 (m, 1H), 4.15-4.12 (t, $J=4.9 \mathrm{~Hz}, 1 \mathrm{H}), 3.96-3.93$ (dd, $J=4.2$, $7.7 \mathrm{~Hz}, 1 \mathrm{H}$ ), 3.81 (s, 3H), 3.73-3.67 (ovrlp m, 3H), 3.49-3.44 (m, 1H), 2.40-2.36 (m, 1H), 2.15-2.05 (ovrlp m, 2H), 1.96-1.90 (ovrlp m, 2H), 1.68-1.63 (ovrlp m, 2H), 0.90-0.83 (m, 1H), 0.61-0.58 (dd, $J=6.0,9.2 \mathrm{~Hz}, 1 \mathrm{H}), 0.54-0.52(\mathrm{t}, J=5.5 \mathrm{~Hz}, 1 \mathrm{H}) ;{ }^{13} \mathrm{C} \mathrm{NMR}\left(125 \mathrm{MHz}, \mathrm{CDCl}_{3}\right) \delta 159.3,130.9$, 129.5, 114.0, 78.4, 74.7, 74.2, 73.0, 67.9, 65.1, 56.4, 55.5, 38.5, 36.5, 26.2, 16.3, 10.9; ESIHRMS $(\mathrm{M}+\mathrm{Na})^{+}$calculated for $\mathrm{C}_{19} \mathrm{H}_{26} \mathrm{O}_{5} \mathrm{Na} 357.1672$, found 357.1679.

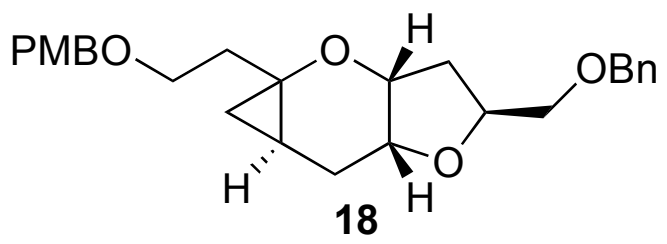

To a ice-cold solution of alcohol VII (100 mg, $0.3 \mathrm{mmol})$ in an anhydrous mixture of THF $(2 \mathrm{~mL})$ and DMF $(0.5$ $\mathrm{mL}$ ) were added $\mathrm{NaH}$ (48 mg, $1.2 \mathrm{mmol}, 60 \%$ dispersion in mineral oil), TBAI (22 $\mathrm{mg}, 0.06 \mathrm{mmol}$ ) sequentially. The resulting suspension was warmed to $\mathrm{rt}$ over $1 \mathrm{~h}$ at which point $\mathrm{BnBr}(0.11 \mathrm{~mL}, 0.90 \mathrm{mmol})$ was added dropwise. The mixture was stirred at $\mathrm{rt}$ until TLC indicated that the reaction was complete, then quenched by addition of saturated $\mathrm{NH}_{4} \mathrm{Cl}$ at 0 ${ }^{\circ} \mathrm{C}$ and extracted with $\mathrm{Et}_{2} \mathrm{O}$. The combined organic extract was washed with water and brine, dried $\left(\mathrm{Na}_{2} \mathrm{SO}_{4}\right)$ and concentrated in vacuo. The residue was purified by chromatography (silica gel, $20 \%$ EtOAc - petroleum ether) to provide $18(101 \mathrm{mg}, 80 \%) .{ }^{1} \mathrm{H} \mathrm{NMR}\left(500 \mathrm{MHz}, \mathrm{CDCl}_{3}\right) \delta$ 7.37-7.28 (m, 7H), $6.88(\mathrm{~d}, \mathrm{~J}=9.5 \mathrm{~Hz}, 2 \mathrm{H}), 4.61-4.57(\mathrm{~d}, J=12.3 \mathrm{~Hz}, 2 \mathrm{H}), 4.47-4.46$ (ovrlp m, 3H), 4.14 (t, $J$ $=5.0 \mathrm{~Hz}, 1 \mathrm{H}), 3.99(\mathrm{dd}, J=4.3,7.7 \mathrm{~Hz}, 1 \mathrm{H}), 3.82(\mathrm{~s}, 3 \mathrm{H}), 3.75-3.68(\mathrm{~m}, 2 \mathrm{H}), 3.49(\mathrm{dd}, J=3.6$, $10.1 \mathrm{~Hz}, 1 \mathrm{H}), 3.46-3.43(\mathrm{dd}, J=5.8,10.2 \mathrm{~Hz}, 1 \mathrm{H}), 2.45-2.40$ (m, $1 \mathrm{H}), 2.19-2.15$ (dd, $J=6.9,13.8$ $\mathrm{Hz}, 1 \mathrm{H}), 2.10(\mathrm{~m}, 1 \mathrm{H}), 1.98-1.93(\mathrm{~m}, 1 \mathrm{H}), 1.68-1.62$ (ovrlp m, 2H), 0.91-0.87 (m, 1H), 0.61-0.58 $(\mathrm{dd}, J=5.9,9.2 \mathrm{~Hz}, 1 \mathrm{H}), 0.53(\mathrm{dt}, J=1.0,5.8 \mathrm{~Hz}, 1 \mathrm{H}) ;{ }^{13} \mathrm{C} \mathrm{NMR}\left(125 \mathrm{MHz}, \mathrm{CDCl}_{3}\right) \delta 159.1$, $138.3,130.8,129.3,128.4,127.7,127.6,113.8,78.3,74.5,74.1,73.4,72.9,72.8,67.7,56.1,55.3$, $38.3,37.3,26.0,16.3,10.9$.

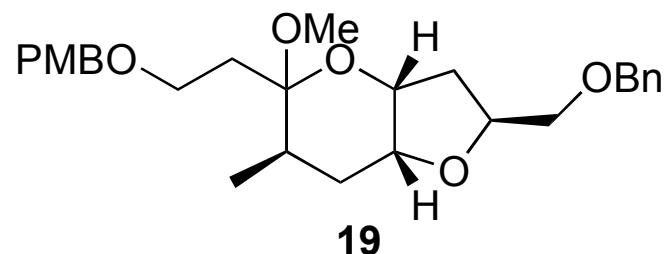

To a solution of cyclopropane $\mathbf{1 8}(85 \mathrm{mg}, 0.2 \mathrm{mmol})$ in anhydrous $\mathrm{MeOH}(2.3 \mathrm{~mL})$ was added IDCP $(235 \mathrm{mg}, 0.50$ $\mathrm{mmol}$ ) in one portion. The reaction mixture was stirred at $\mathrm{rt}$ for $1 \mathrm{~h}$ then quenched with saturated $\mathrm{Na}_{2} \mathrm{~S}_{2} \mathrm{O}_{3}$ and extracted with ether. The combined organic extract was washed with brine, dried $\left(\mathrm{Na}_{2} \mathrm{SO}_{4}\right)$ and concentrated under reduced pressure. The crude product was dried by distillation of the benzene-water azeotrope ( 3 times). To a flask containing the residue was added 
dry toluene $(3 \mathrm{~mL})$, AIBN $(3 \mathrm{mg}, 0.04 \mathrm{mmol})$ and $\mathrm{Bu}_{3} \mathrm{SnH}(0.1 \mathrm{~mL}, 0.36 \mathrm{mmol})$ sequentially. The reaction mixture was heated at reflux for $2 \mathrm{~h}$ then concentrated in vacuo. Purification of the residue by chromatography (silica gel, $20 \%$ EtOAc - petroleum ether) afforded compound 19 (77 mg, $80 \%) .[\alpha]_{\mathrm{D}}{ }^{24} 0.50\left(c 1.0, \mathrm{CHCl}_{3}\right) ;{ }^{1} \mathrm{H}$ NMR $\left(500 \mathrm{MHz}, \mathrm{CDCl}_{3}\right) \delta$ 7.39-7.28 (m, 7H), $6.89(\mathrm{dd}, J=$ $2.0,6.7 \mathrm{~Hz}, 2 \mathrm{H}), 4.66-4.59(\mathrm{~d}, J=12.3 \mathrm{~Hz}, 2 \mathrm{H}), 4.44(\mathrm{~s}, 2 \mathrm{H}), 4.42-4.38(\mathrm{~m}, 1 \mathrm{H}), 4.03(\mathrm{t}, J=2.4$ $\mathrm{Hz}, 1 \mathrm{H}$ ), 3.95-3.93 (dd, $J=2.2,4.6 \mathrm{~Hz}, 1 \mathrm{H}$ ), 3.82 (s, 3H), 3.58-3.53 (ovrlp m, 3H), 3.51-3.47 (dd, $J$ $=6.0,10.2 \mathrm{~Hz}, 1 \mathrm{H}), 3.25(\mathrm{~s}, 3 \mathrm{H}), 2.10(\mathrm{~m}, 1 \mathrm{H}), 2.05-2.02(\mathrm{~m}, 1 \mathrm{H}), 1.96-1.90(\mathrm{~m}, 2 \mathrm{H}), \quad 1.84-1.77$ (ovrlp m, 3H), 0.90-0.88 (d, $J=6.8 \mathrm{~Hz}, 3 \mathrm{H}),{ }^{13} \mathrm{C} \mathrm{NMR} \mathrm{(125.0} \mathrm{MHz,} \mathrm{CDCl}_{3}$ ) $\delta 159.1,138.4,130.6$, 129.3, 128.4, 127.7, 127.6, 113.8, 100.1, 77.6, 76.5, 73.4, 73.0, 72.8, 71.8, 66.6, 55.3, 47.9, 36.4, 33.7, 29.6, 29.2, 15.7; ESIHRMS (M-CH 3$)^{+}$calculated for $\mathrm{C}_{26} \mathrm{H}_{33} \mathrm{O}_{5} \quad 425.2322$, found 425.2323.

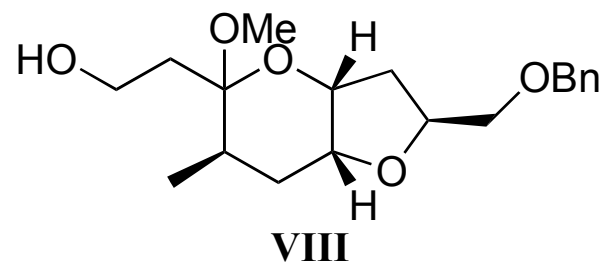

DDQ $(57 \mathrm{mg}, 0.25 \mathrm{mmol})$ was added in one portion, at $0{ }^{\circ} \mathrm{C}$, to a mixture of compound $19(63 \mathrm{mg}, 0.10 \mathrm{mmol})$ in $\mathrm{CH}_{2} \mathrm{Cl}_{2}(1.0$ $\mathrm{mL})$ and $\mathrm{pH} 7$ buffer $\left(0.2 \mathrm{~mL}\right.$ of a $1 \mathrm{M}$ solution of $\mathrm{NaH}_{2} \mathrm{PO}_{4} /$ $\mathrm{Na}_{2} \mathrm{HPO}_{4}$ buffer). After $10 \mathrm{~min}$, the reaction mixture was warmed to rt, stirred at this temperature for $2 \mathrm{~h}$, quenched with saturated aqueous $\mathrm{NaHCO}_{3}$, and extracted with EtOAc. The organic phase was washed with brine, dried $\left(\mathrm{Na}_{2} \mathrm{SO}_{4}\right)$ and concentrated in vacuo. Purification of the residue by chromatography (silica gel, 20\% EtOAc - petroleum ether) afforded alcohol VII (53 mg, 83\%) as a colorless oil. ${ }^{1} \mathrm{H}$ NMR $\left(500 \mathrm{MHz}, \mathrm{CDCl}_{3}\right) \delta 7.38-7.27(\mathrm{~m}, 5 \mathrm{H}), 4.60(\mathrm{~d}, J=12.3 \mathrm{~Hz}, 2 \mathrm{H}), 4.43(\mathrm{~m}, 1 \mathrm{H}), 4.08(\mathrm{t}, J=2.1 \mathrm{~Hz}$, $1 \mathrm{H}), 3.95(\mathrm{dd}, J=2.4,4.8 \mathrm{~Hz}, 1 \mathrm{H}), 3.80(\mathrm{dt}, J=3.4,9.5 \mathrm{~Hz}, 1 \mathrm{H}), 3.68(\mathrm{~m}, 1 \mathrm{H}), 3.55(\mathrm{dd}, J=2.4,4.8$ $\mathrm{Hz}, 1 \mathrm{H}), 3.47$ (dd, $J=2.4,4.8 \mathrm{~Hz}, 1 \mathrm{H}), 3.29$ (s, 3H), 2.76 (d, $J=7.7 \mathrm{~Hz}, 1 \mathrm{H}), 2.41-2.14(\mathrm{~m}, 2 \mathrm{H})$, 2.04-2.02 (dd, $J=6.4,13.4 \mathrm{~Hz}, 1 \mathrm{H}), 1.94(\mathrm{~m}, 1 \mathrm{H}), 1.85-1.83(\mathrm{~m}, 1 \mathrm{H}), 1.77$ (dt, $J=3.7,14.4 \mathrm{~Hz}$, $1 \mathrm{H}), 0.86(\mathrm{~d}, J=6.9 \mathrm{~Hz}, 3 \mathrm{H}) ;{ }^{13} \mathrm{C} \mathrm{NMR}\left(125.0 \mathrm{MHz}, \mathrm{CDCl}_{3}\right) \delta 138.5,128.6,127.9,127.8,102.4$, 77.6, 76.5, 73.6, 72.9, 72.6, 58.9, 48.3, 36.4, 34.5, 29.6, 28.7, 15.8 .

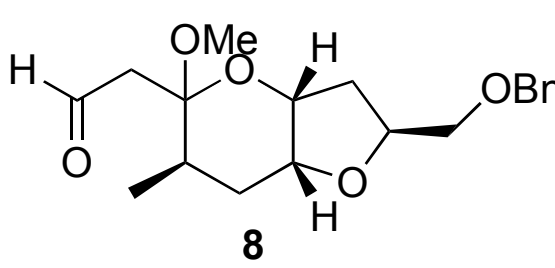

To a mixture of compound VII (36mg, $0.074 \mathrm{mmol}$ ) in gel, $15 \%$ EtOAc - petroleum ether) afforded $8(33 \mathrm{mg}, 80 \%)$ as a colorless oil. ${ }^{1} \mathrm{H}$ NMR $(500 \mathrm{MHz}$, $\left.\mathrm{CDCl}_{3}\right) \delta 9.73(\mathrm{~m}, 1 \mathrm{H}), 7.36-7.28(\mathrm{~m}, 5 \mathrm{H}), 4.60(\mathrm{~d}, J=12.3 \mathrm{~Hz}, 2 \mathrm{H}), 4.42(\mathrm{~m}, 1 \mathrm{H}), 4.11(\mathrm{~m}, 1 \mathrm{H})$, 3.98-3.97 (dd, $J=2.6,5.0 \mathrm{~Hz}, 1 \mathrm{H}), 3.56-3.53(\mathrm{dd}, J=3.5,10.2 \mathrm{~Hz}, 1 \mathrm{H}), 3.50-3.47$ (dd, $J=5.8,10.2$ $\mathrm{Hz}, 1 \mathrm{H}), 3.29$ (s, 3H), $2.81-2.78$ ( dd, $J=2.0,14.6 \mathrm{~Hz}, 1 \mathrm{H}), 2.56-2.52$ (dd, $J=2.0,14.6 \mathrm{~Hz}, 1 \mathrm{H}$ ), 2.09-2.05 (dd, $J=6.3,13.2 \mathrm{~Hz}, 1 \mathrm{H}), 2.00(\mathrm{~m}, 1 \mathrm{H}), 1.93-1.90(\mathrm{~m}, 1 \mathrm{H}), 1.84-1.82(\mathrm{~m}, 2 \mathrm{H}), 0.90(\mathrm{~d}, J$ 
$=6.8 \mathrm{~Hz}, 3 \mathrm{H}) ;{ }^{13} \mathrm{C} \mathrm{NMR}\left(125 \mathrm{MHz}, \mathrm{CDCl}_{3}\right) \delta 201.4,138.3,128.4,127.7,127.6,99.6,77.6,76.1$, $73.4,72.8,72.3,48.5,47.9,36.1,31.6,29.5,15.2$.

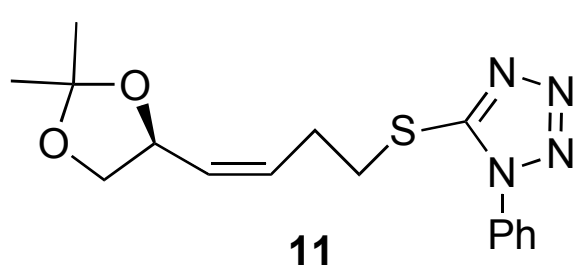

11

n-BuLi (10.4 mL of a $2.5 \mathrm{M}$ solution in hexane, $25.6 \mathrm{mmol})$ $\mathrm{N}$ was added dropwise at $-78{ }^{\circ} \mathrm{C}$ to a well-stirred suspension of $\mathrm{N}$ phosphonium salt $10(13.3 \mathrm{~g}, 25.6 \mathrm{mmol})$ in a 2:1 mixture of THF:HMPA $(150 \mathrm{~mL})$. The resulting dark brown solution was stirred at this temperature for $5 \mathrm{~min}$, at which point a solution of aldehyde $9(2.80 \mathrm{~g}, 21.5 \mathrm{mmol})$ in dry THF $(20 \mathrm{~mL})$ was slowly introduced. The reaction mixture was warmed to $0{ }^{\circ} \mathrm{C}$, stirred at this temperature for $3 \mathrm{~h}$ then quenched by addition of saturated aqueous $\mathrm{NH}_{4} \mathrm{Cl}$. The mixture was extracted with ether, dried $\left(\mathrm{Na}_{2} \mathrm{SO}_{4}\right)$ and concentrated in vacuo. Purification of the residue by chromatography (silica gel, 10\% EtOAc - petroleum ether) afforded the alkene product as a colorless oil $\left(4.30 \mathrm{~g}, 70 \%, \mathrm{R}_{\mathrm{f}}=0.55\right)$. To a solution of this material ( 924 $\mathrm{mg}, 3.23 \mathrm{mmol})$ in anhydrous THF $(6 \mathrm{~mL})$ was added TBAF $\left(6.46 \mathrm{~mL}, 1.0 \mathrm{M}\right.$ in THF) at $0{ }^{\circ} \mathrm{C}$. The mixture was warmed to $\mathrm{rt}$, stirred at this temperature for $30 \mathrm{~min}$, then diluted with saturated aqueous $\mathrm{NH}_{4} \mathrm{Cl}$ and extracted with EtOAc. The organic extract was washed with brine, dried $\left(\mathrm{Na}_{2} \mathrm{SO}_{4}\right)$ and concentrated in vacuo. Purification of the residue by chromatography (silica gel, $30 \%$ EtOAc - petroleum ether) afforded the desilylated product as a colorless oil $\left(500 \mathrm{mg}, 95 \%, \mathrm{R}_{\mathrm{f}}=\right.$ $0.10)$.

To a stirred solution of alcohol from the previous step (231 mg, $1.34 \mathrm{mmol})$ in anhydrous THF (5 $\mathrm{mL}$ ) was added $\mathrm{PPh}_{3}(528.4 \mathrm{mg}, 2.01 \mathrm{mmol})$ and 1-phenyl-1H-tetrazole-5-thiol (358 mg, 2.01 mmol). The mixture was cooled to $0{ }^{\circ} \mathrm{C}$ then DIAD $(0.40 \mathrm{~mL}, 2.01 \mathrm{mmol})$ was added dropwise. The resulting yellow solution was slowly warmed up to rt until TLC indicated complete disappearance of the starting material. The mixture was concentrated in vacuo and the residue purified by chromatography (silica gel, 20\% EtOAc - petroleum ether) to provide thioether 11 (356 $\mathrm{mg}, 80 \%)$ as a colorless oil. $[\alpha]_{\mathrm{D}}{ }^{24}-0.76\left(c 1.0, \mathrm{CHCl}_{3}\right) ;{ }^{1} \mathrm{H}$ NMR $\left(500 \mathrm{MHz}, \mathrm{CDCl}_{3}\right) \delta$ 7.60-7.57 (m, 5H), 5.69$5.67(\mathrm{~m}, 1 \mathrm{H}), 5.60-5.56(\mathrm{~m}, 1 \mathrm{H}), 4.82(\mathrm{q}, J=6.2 \mathrm{~Hz}, 1 \mathrm{H}), 4.07-4.04(\mathrm{dd}, J=6.2,8.1 \mathrm{~Hz}, 1 \mathrm{H}), 3.54-$ $3.51(\mathrm{t}, J=7.9 \mathrm{~Hz}, 1 \mathrm{H}), 3.47-3.43(\mathrm{~m}, 2 \mathrm{H}), 2.77-2.69(\mathrm{~m}, 2 \mathrm{H}), 1.42(\mathrm{~s}, 3 \mathrm{H}), 1.37(\mathrm{~s}, 3 \mathrm{H}) ;{ }^{13} \mathrm{C}$ NMR $\left(125 \mathrm{MHz}, \mathrm{CDCl}_{3}\right) \delta 154.0,133.6,130.8,130.5,130.2,129.8,123.9,109.3,71.7,69.3,32.7$, 27.4, 26.7, 25.8; ESIHRMS (M- $\left.\mathrm{C}_{3} \mathrm{H}_{5} \mathrm{O}\right)^{+}$calculated for $\mathrm{C}_{13} \mathrm{H}_{15} \mathrm{~N}_{4} \mathrm{SO} 275.0961$, found 275.0969.

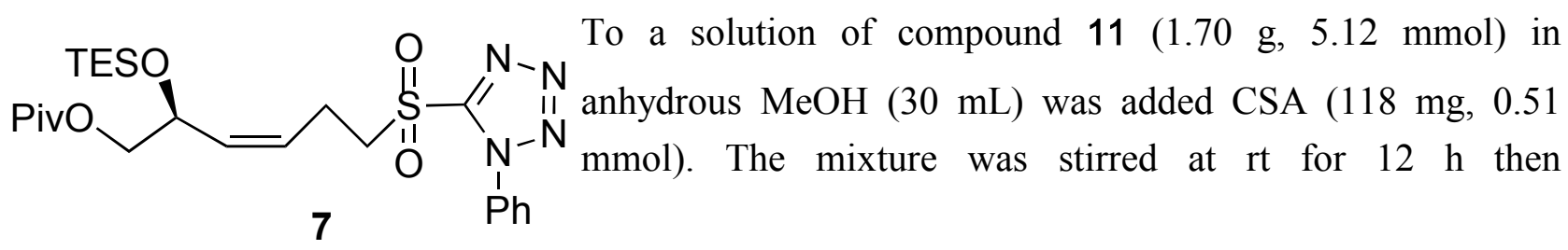


concentrated under reduced pressure. Purification of the residue by chromatography (silica gel, $60 \%$ EtOAc - petroleum ether) afforded the derived diol $\left(1.35 \mathrm{~g}, 90 \%, \mathrm{R}_{\mathrm{f}}=0.10\right)$ as a colorless oil. To a solution of this material $(1.1 \mathrm{~g}, 3.77 \mathrm{mmol})$ in anhydrous $\mathrm{CH}_{2} \mathrm{Cl}_{2}(20 \mathrm{~mL})$ was added DMAP $(92$ $\mathrm{mg}, 0.75 \mathrm{mmol})$ and dry pyridine $(0.62 \mathrm{~mL}, 7.54 \mathrm{mmol})$ sequentially. The mixture was cooled to 0 ${ }^{\circ} \mathrm{C}$ and pivaloyl chloride $(0.56 \mathrm{~mL}, 4.52 \mathrm{mmol})$ was added. The reaction mixture was warmed to rt, stirred for $4 \mathrm{~h}$ at this temperature, then diluted with saturated aqueous $\mathrm{NH}_{4} \mathrm{Cl}$ and extracted with EtOAc. The organic phase was washed with brine, dried $\left(\mathrm{Na}_{2} \mathrm{SO}_{4}\right)$ and concentrated in vacuo. Purification of the residue by chromatography (silica gel, 15\% EtOAc - petroleum ether) afforded the secondary alcohol derivative $\left(1.16 \mathrm{~g}, 82 \%, \mathrm{R}_{\mathrm{f}}=0.20\right)$ as a colorless oil.

TESCl $(0.49 \mathrm{~mL}, 2.87 \mathrm{mmol})$ was added in one portion to a mixture of the product from the previous step (720 mg, $1.9 \mathrm{mmol})$, DMAP (585 mg, $4.8 \mathrm{mmol}$ ) and anhydrous DMF (3 mL). The reaction mixture was stirred at $\mathrm{rt}$ for $30 \mathrm{~min}$ then diluted with saturated aqueous $\mathrm{NH}_{4} \mathrm{Cl}$, and extracted with EtOAc. The organic extract was washed with brine, dried $\left(\mathrm{Na}_{2} \mathrm{SO}_{4}\right)$ and concentrated in vacuo. Purification of the residue by chromatography (silica gel, 5\% EtOAc - petroleum ether) afforded the 6-O-pivaloyl-5-O-triethysilylsulfide-4-hexen-thioether derivative $\left(745 \mathrm{mg}, 80 \%, \mathrm{R}_{\mathrm{f}}=\right.$ $0.20)$ as a colorless oil.

To a flask equipped with ammonium molybdate $(706 \mathrm{mg}, 0.57 \mathrm{mmol}$ ) was added $30 \%$ aqueous $\mathrm{H}_{2} \mathrm{O}_{2}(5 \mathrm{~mL})$ in one portion until a bright yellow solution was generated. The yellow solution was added dropwise at $0{ }^{\circ} \mathrm{C}$, to a separate flask charged with a solution of the thioether from the previous step $(700 \mathrm{mg}, 1.43 \mathrm{mmol})$ in ethanol $(50 \mathrm{~mL})$. The reaction mixture was slowly warmed to $\mathrm{rt}$, maintained at this temperature for $1 \mathrm{~h}$, then diluted with water and extracted with $\mathrm{CH}_{2} \mathrm{Cl}_{2}$. The organic extract was dried $\left(\mathrm{Na}_{2} \mathrm{SO}_{4}\right)$ amd concentrated in vacuo. Purification of the residue by chromatography (silica gel, 5\% EtOAc - petroleum ether) afforded sulfone 7 (356 $\mathrm{mg}, 80 \%)$ as a colorless oil. $[\alpha]_{\mathrm{D}}^{24}-1.1$ (c 1.0, $\left.\mathrm{CHCl}_{3}\right)$; FTIR(neat) 3069, 2958, 2911, 2876, 1726, 1598, 1498, $1461,1347,1285,1239,1151,1111 \mathrm{~cm}^{-1} ;{ }^{1} \mathrm{H}$ NMR $\left(500 \mathrm{MHz}, \mathrm{CDCl}_{3}\right) \delta 7.74(\mathrm{~m}, 2 \mathrm{H}), 7.65-7.62$ (m, 3H), 5.61-5.52 (m, 2H), 4.72-4.68 (dd, $J=5.9,13.8 \mathrm{~Hz}, 1 \mathrm{H}), 3.98(\mathrm{~d}, J=5.8 \mathrm{~Hz}, 2 \mathrm{H}), 3.84-3.81$ (t, $J=8.0 \mathrm{~Hz}, 2 \mathrm{H}), 2.89-2.80(\mathrm{~m}, 2 \mathrm{H}), 1.21(\mathrm{~s}, 9 \mathrm{H}), 0.99-0.95$ (t, $J=8.0 \mathrm{~Hz}, 9 \mathrm{H}), 0.56-0.60$ (q, $J$ $=7.9,6 \mathrm{H}) ;{ }^{13} \mathrm{C} \mathrm{NMR}\left(125 \mathrm{MHz}, \mathrm{CDCl}_{3}\right) \delta 178.4,153.3,134.1,133.0,131.5,129.8,125.4,125.0$, 68.0, 66.7, 55.4, 38.8, 27.2, 21.3, 6.8, 4.8; ESIHRMS $(\mathrm{M}+\mathrm{Na})^{+}$calculated for $\mathrm{C}_{24} \mathrm{H}_{38} \mathrm{~N}_{4} \mathrm{O}_{5} \mathrm{NaSi} \mathrm{S}$ 545.2224, found 545.2225.

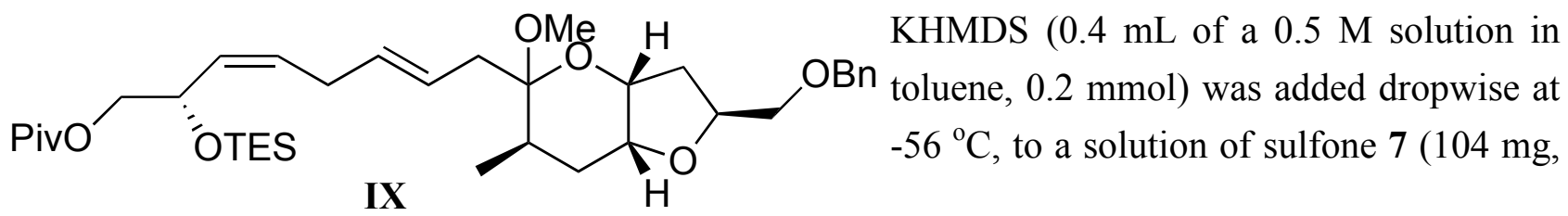


$0.2 \mathrm{mmol})$ in dry DME. The resulting bright yellow- orange solution was maintained at $-60{ }^{\circ} \mathrm{C}$ for $40 \mathrm{~min}$ and a solution of aldehyde $8(33 \mathrm{mg}, 0.1 \mathrm{mmol})$ in DME $(1.0 \mathrm{~mL})$ slowly added. The light yellow reaction mixture was stirred at $-50{ }^{\circ} \mathrm{C}$ for $90 \mathrm{~min}$, then warmed to $0{ }^{\circ} \mathrm{C}$ over $90 \mathrm{~min}$. The cooling bath was removed and the reaction was allowed to warm to $\mathrm{rt}$ during which time appearance of a white precipitate was observed. After stirring at $\mathrm{rt}$ for an additional $90 \mathrm{~min}$, the reaction was partitioned between $\mathrm{H}_{2} \mathrm{O}$ and $\mathrm{Et}_{2} \mathrm{O}$. The aqueous phase was extracted with $\mathrm{EtOAc}$ and the combined organic extract washed with $\mathrm{H}_{2} \mathrm{O}$ and brine, dried $\left(\mathrm{Na}_{2} \mathrm{SO}_{4}\right)$, and concentrated in vacuo. Purification of the residue by chromatography (silica gel, $5 \%$ EtOAc - petroleum ether) afforded diene IX (45 $\mathrm{mg}, 88 \%)$ as a colorless oil. ${ }^{1} \mathrm{H}$ NMR $\left(500 \mathrm{MHz}, \mathrm{CDCl}_{3}\right) \delta$ 7.36-7.28 (m, 5H), 5.45-5.36 (m, 4H), $4.70(\mathrm{~m}, 1 \mathrm{H}), 4.63-4.60(\mathrm{~d}, J=12.3 \mathrm{~Hz}, 2 \mathrm{H}), 4.43(\mathrm{~m}, 1 \mathrm{H}), 4.03(\mathrm{~m}, 1 \mathrm{H}), 3.95$ (ovrlp m, 3H), 3.55 (dd, $J=3.5,10.2 \mathrm{~Hz}, 1 \mathrm{H}), 3.49(\mathrm{dd}, J=5.8,10.1 \mathrm{~Hz}, 1 \mathrm{H}), 3.24(\mathrm{~s}, 3 \mathrm{H}), 2.81(\mathrm{~m}, 2 \mathrm{H}), 2.50(\mathrm{dd}, J=$ 2.7, $13.2 \mathrm{~Hz}, 1 \mathrm{H}), 2.20$ (dd, $J=7.4,13.8 \mathrm{~Hz}, 1 \mathrm{H}), 2.04$ (ovrlp m, 2H), $1.85(\mathrm{~m}, 1 \mathrm{H}), 1.78-1.73$ (m, 2H), $1.21(\mathrm{~s}, 9 \mathrm{H}), 0.96$ (t, $J=7.9 \mathrm{~Hz}, 9 \mathrm{H}), 0.82$ (d, $J=6.8 \mathrm{~Hz}, 3 \mathrm{H}), 0.60$ (q, $J=7.9 \mathrm{~Hz}, 6 \mathrm{H}) ;{ }^{13} \mathrm{C}$ NMR $\left(125 \mathrm{MHz}, \mathrm{CDCl}_{3}\right) \delta 178.7,138.6,130.4,130.2,128.5,128.0,127.8,126.8,101.0,77.8,76.8$, $73.6,73.1,72.1,68.3,66.7,48.2,39.0,37.8,36.6,31.5,29.9,29.3,27.5,15.3,7.0,5.1$.

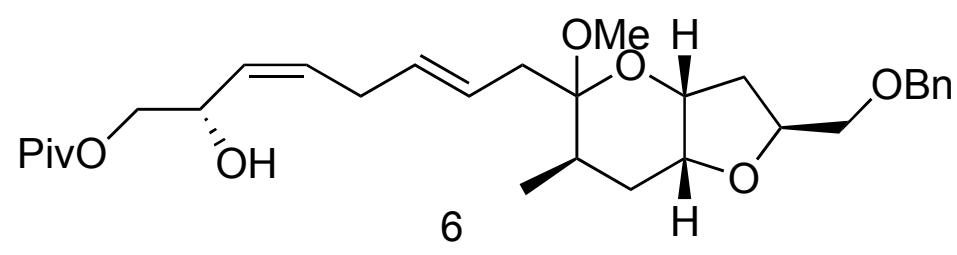

To a mixture of compound IX (44 mg, $0.076 \mathrm{mmol})$ in anhydrous THF $(1.0 \mathrm{~mL})$ at $0^{\circ} \mathrm{C}$ were added TBAF $(0.23 \mathrm{~mL}$ of a 1 $M$ solution in THF, $0.23 \mathrm{mmol}$ ) and HOAc $(0.013 \mathrm{~mL}, 0.228 \mathrm{mmol})$. The

reaction mixture was stirred at $\mathrm{rt}$ for $1 \mathrm{~h}$, then quenched with saturated aqueous $\mathrm{NH}_{4} \mathrm{Cl}$ and extracted with EtOAc. The organic phase was washed with brine, dried $\left(\mathrm{Na}_{2} \mathrm{SO}_{4}\right)$ and concentrated in vacuo. Purification of the residue by chromatography (silica gel, 15\% EtOAc - petroleum ether) afforded alcohol 6 (31 mg, 82\%) as a colorless oil. FTIR (neat) 3447, 3028, 2958, 2926, 2873, 1729 , $1458,1282,1157,1073 \mathrm{~cm}^{-1} ;{ }^{1} \mathrm{H}$ NMR $\left(500 \mathrm{MHz}, \mathrm{CDCl}_{3}\right) \delta$ 7.36-7.28 (m, 5H), 5.64-5.59 (m, 1H), 5.49-5.52 (m, 3H), 4.71-4.64 (m, 1H), 4.61-4.58 (d, $J=12.3 \mathrm{~Hz}, 2 \mathrm{H}), 4.46-4.41(\mathrm{~m}, 1 \mathrm{H}), 4.10-4.07$ (dd, $J=4.2,11.3 \mathrm{~Hz}, 1 \mathrm{H}), 4.06-3.99$ (ovrlp m, 2H), $3.92(\mathrm{~m}, 1 \mathrm{H}), 3.56-3.53$ (dd, $J=3.6,10.2 \mathrm{~Hz}$, $1 \mathrm{H}), 3.50-3.49$ (dd, $J=5.8,10.2 \mathrm{~Hz}, 1 \mathrm{H}), 3.24(\mathrm{~s}, 3 \mathrm{H}), 2.89-2.87(\mathrm{~m}, 1 \mathrm{H}), 2.79-2.78(\mathrm{~m}, 1 \mathrm{H}), 2.51-$ $2.48(\mathrm{~m}, 1 \mathrm{H}), 2.35$ (br, $1 \mathrm{H}), 2.22-2.19(\mathrm{~m}, 1 \mathrm{H}), 2.06-1.98$ (ovrlp m, 2H), 1.86-1.83 (m, 1H), 1.77$1.74(\mathrm{~m}, 2 \mathrm{H}), 1.23(\mathrm{~s}, 9 \mathrm{H}), 0.83(\mathrm{~d}, J=6.8 \mathrm{~Hz}, 3 \mathrm{H}) ;{ }^{13} \mathrm{C} \mathrm{NMR}\left(125 \mathrm{MHz}, \mathrm{CDCl}_{3}\right) \delta 178.8,138.5$, 132.1, 130.1, 129.0, 128.6, 128.0, 127.8, 126.7, 101.0, 77.8, 76.7, 73.7, 73.2, 72.0, 67.9, 66.4, 48.2, $39.1,37.5,36.6,31.2,29.9,29.8,29.0,27.4,15.3$; ESIHRMS $(\mathrm{M}+\mathrm{Na})^{+}$calculated for $\mathrm{C}_{30} \mathrm{H}_{44} \mathrm{O}_{7} \mathrm{Na}$ 539.2979 , found 539.2980 .

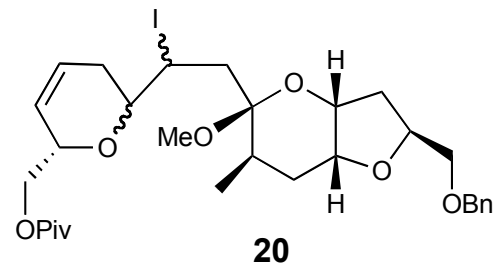

To a mixture of diene-ol $6(7 \mathrm{mg}, 0.015 \mathrm{mmol})$ in dry $\mathrm{CH}_{2} \mathrm{Cl}_{2}(0.8$ 
$\mathrm{mL})$ was added IDCP $(18 \mathrm{mg}, 0.04 \mathrm{mmol})$ in one portion. The reaction mixture was stirred at $\mathrm{rt}$ for $25 \mathrm{~min}$ then quenched with saturated aqueous $\mathrm{Na}_{2} \mathrm{~S}_{2} \mathrm{O}_{3}$ and extracted with ether. The organic extract was dried $\left(\mathrm{Na}_{2} \mathrm{SO}_{4}\right)$ and concentrated under reduced pressure. Purification of the residue by chromatography (silica gel, 10\% EtOAc - petroleum ether) afforded iodide $\mathbf{2 0}$ as an approximately 1:1 mixture of two diastereomers $(7.7 \mathrm{mg}, 80 \%)$. For more polar component: colorless oil; ${ }^{1} \mathrm{H}$ NMR (500 MHz, $\left.\mathrm{C}_{6} \mathrm{D}_{6}\right) \delta$ 7.38-7.30 (m, 5H), 5.62-5.57 (m, 1H), 5.31-5.25 (m, 1H), 4.62-4.57 (m, $1 \mathrm{H}), 4.44-4.39$ (d, $J=12.3 \mathrm{~Hz}, 2 \mathrm{H}), 4.17-4.14$ (dd, $J=3.1,12.3 \mathrm{~Hz}, 1 \mathrm{H}), 3.86-3.83$ (m, 2H), 3.713.67 (dd, $J=6.0,12.4 \mathrm{~Hz}, 1 \mathrm{H}), 3.48-3.37$ (ovrlp m, 3H), 3.07 (s, 3H), 2.88-2.86 (dd, $J=3.0,10.2$ $\mathrm{Hz}, 1 \mathrm{H}), 2.79(\mathrm{~m}, 1 \mathrm{H}), 2.54-2.50(\mathrm{~m}, 1 \mathrm{H}), 2.34-2.29(\mathrm{~m}, 1 \mathrm{H}), 2.27-2.20(\mathrm{~m}, 2 \mathrm{H}), 2.18-2.14(\mathrm{~m}, 1 \mathrm{H})$, 2.09-2.03 (m, 1H), 1.87-1.77 (ovrlp m, 3H), $1.14(\mathrm{~s}, 9 \mathrm{H}), 0.95$ (d, $J=6.8 \mathrm{~Hz}, 3 \mathrm{H}) ;{ }^{13} \mathrm{C}$ NMR $(125$ $\left.\mathrm{MHz}_{,} \mathrm{CDCl}_{3}\right) \delta 178.8,139.5,129.4,129.2,129.0,128.9,101.2,78.3,77.0,73.8,73.0,64.3,60.7$, 59.8, 48.2, 39.7, 39.2, 38.3, 37.3, 33.2, 32.7, 30.6, 30.0, 15.9; ESIHRMS (M+Na) ${ }^{+}$calculated for $\mathrm{C}_{30} \mathrm{H}_{43} \mathrm{O}_{7} \mathrm{NaI}$ 665.1945, found 665.1937.

For less polar component: colorless oil; ${ }^{1} \mathrm{H}$ NMR $\left(500 \mathrm{MHz}, \mathrm{CDCl}_{3}\right) \delta$ 7.38-7.30 (m, 5H), 6.015.97 (m, 1H), 5.77-5.73 (m, 1H), 4.63-4.57 (m, 2H), 4.49 (m, 1H), 4.46-4.38 (ovrlp m, 3H), 4.043.94 (ovrlp m, 2H), 3.92 (m, 1H), 3.57-3.54 (dd, $J=3.7,10.3 \mathrm{~Hz}, 1 \mathrm{H}), 3.51-3.48$ (dd, $J=5.3,10.2$ $\mathrm{Hz}, 1 \mathrm{H}), 3.34-3.30(\mathrm{~m}, 1 \mathrm{H}), 3.24(\mathrm{~s}, 3 \mathrm{H}), 2.59-2.54$ (dd, $J=8.9,15.1 \mathrm{~Hz}, 1 \mathrm{H}), 2.37-2.33$ (ovrlp m, 2H), 2.26-2.24 (ovrlp m, 2H), 1.95-1.87 (ovrlp m, 3H), 1.83-1.78 (m, 1H), 1.23 (s, 9H), 0.96-0.94 $(\mathrm{d}, J=6.8 \mathrm{~Hz}, 3 \mathrm{H}) ;{ }^{13} \mathrm{C} \mathrm{NMR}\left(125 \mathrm{MHz}, \mathrm{CDCl}_{3}\right) \delta 177.1,138.5,128.3,127.7,127.6,127.5,126.3$, 124.9, 101.4, 77.3, 76.1, 73.3, 72.8, 72.4, 72.3, 70.2, 64.0, 47.7, 41.0, 36.0, 34.4, 34.0, 29.3, 28.4, 28.1, 27.2, 15.9; ESIHRMS (M+Na) ${ }^{+}$calculated for $\mathrm{C}_{30} \mathrm{H}_{43} \mathrm{O}_{7} \mathrm{NaI} 665.1945$, found 665.1949.

\section{Synthesis and physical data for title compound}

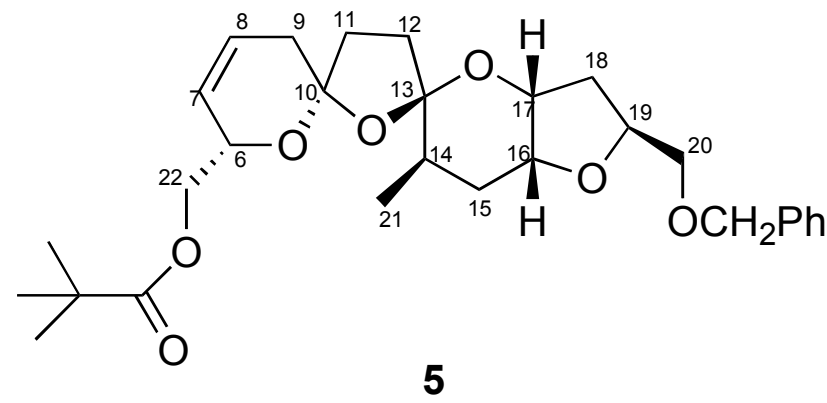

To a mixture of dienol $6(5 \mathrm{mg}, 0.01 \mathrm{mmol})$ in dry $\mathrm{CH}_{2} \mathrm{Cl}_{2}(0.4 \mathrm{~mL})$ was added IDCP $(15 \mathrm{mg}, 0.03$ $\mathrm{mmol}$ ) in one portion. The reaction mixture was stirred at $\mathrm{rt}$ for $25 \mathrm{~min}$ then quenched with saturated aqueous $\mathrm{Na}_{2} \mathrm{~S}_{2} \mathrm{O}_{3}$ and extracted with ether. The organic extract was dried $\left(\mathrm{Na}_{2} \mathrm{SO}_{4}\right)$ and concentrated under reduced pressure. The residue was dissolved in anhydrous methanol $(0.4 \mathrm{~mL})$ and AgOTf $(7.7 \mathrm{mg}, 0.03 \mathrm{mmol})$ was added in one portion to the solution. The mixture was stirred at $\mathrm{rt}$ for $20 \mathrm{~min}$, then PPTS (5 mg, 0.02 $\mathrm{mmol})$ and water $(0.01 \mathrm{~mL})$ added sequentially, and stirring continued at $\mathrm{rt}$ for an additional $6 \mathrm{~h}$. 
The mixture was then diluted with saturated aqueous $\mathrm{Na}_{2} \mathrm{~S}_{2} \mathrm{O}_{3}$ and extracted with ether. The organic phase was washed with saturated aqueous $\mathrm{NaHCO}_{3}$, water and brine, dried $\left(\mathrm{Na}_{2} \mathrm{SO}_{4}\right)$ and concentrated in vacuo. Purification of the residue by chromatography (silica gel, 10\% EtOAc petroleum ether) afforded spiroketal 5 ( $3 \mathrm{mg}, 62 \%, 2$ steps) as a colorless oil. $[\alpha]_{\mathrm{D}}{ }^{24}-4.3(c 0.20$, $\mathrm{CHCl}_{3}$ ); FTIR (neat) 3036, 2961, 2926, 2856, 1732, 1455, 1277, 1154, 1105, 1070, 1029, $988 \mathrm{~cm}^{-1}$;

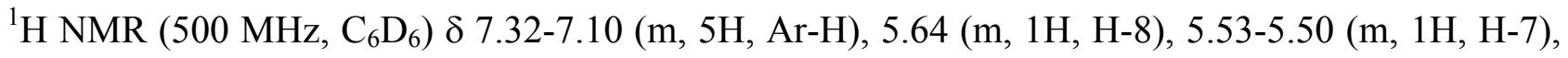
4.69 (m, 1H, H-6), 4.61-4.56 (m, 1H, H-19), 4.41 (s, $2 \mathrm{H}, \mathrm{CH}_{2} \mathrm{Ph}$ ), 4.29-4.25 (dd, $J=6.8,11.2 \mathrm{~Hz}$, 1H, H-22), 4.16-4.13 (ovrlp m, 2H, H-22, H-17), 3.82 (q, $J=2.5 \mathrm{~Hz}, 1 \mathrm{H}, \mathrm{H}-16$ ), 3.43-3.41 (dd, $J=$ 4.0, 10.1Hz, 1H, H-20), 3.38-3.37 (dd, $J=4.8,10.1 \mathrm{~Hz}, 1 \mathrm{H}, \mathrm{H}-20$ ), 2.33-2.23 (ovrlp m, 3H, H-9, H14, H-11 or H-12), 2.13-2.08 (m, 1H, H-11 or H-12), 2.03-1.92 (ovrlp m, 4H, H-9, H-18, H-15, H11 or H-12), 1.84-1.79 (m, 1H, H-18), 1.76-1.67 (ovrlp m, 2H, H-15, H-11 or H-12), 1.19 (s, 9H, $\left.\left[\left(\mathrm{CH}_{3}\right)_{3} \mathrm{C}\right]\right), 0.94-0.92(\mathrm{~d}, 3 \mathrm{H}, J=6.8 \mathrm{~Hz}, \mathrm{H}-21) ;{ }^{13} \mathrm{C} \mathrm{NMR}\left(125 \mathrm{MHz}, \mathrm{CDCl}_{3}\right) \delta 177.9(\mathrm{C}=\mathrm{O})$, 139.7 (Ar), 128.0 (Ar buried under $\mathrm{C}_{6} \mathrm{D}_{6}$ signal) 125.9 (C-7), 125.1 (C-8), 110.9 (C-10 or C-13), 106.0 (C-10 or C-13), 78.2 (C-19), 77.1 (C-16), 73.8 (C-20), $73.7\left(\mathrm{OCH}_{2} \mathrm{Ph}\right), 73.1$ (C-17), 69.2 (C6), $66.6(\mathrm{C}-22) 39.2\left[\left(\mathrm{CH}_{3}\right)_{3} \mathrm{C}\right], 37.3$ (C-11 or C-12), 37.0 (C-18), 35.6 (C-9), 32.9 (C-11 or C-12), $32.2(\mathrm{C}-15), 30.4(\mathrm{C}-14), 27.7\left[\left(\mathrm{CH}_{3}\right)_{3} \mathrm{C}\right], 16.9(\mathrm{C}-21)$; ESIHRMS $(\mathrm{M}+\mathrm{Na})^{+}$calculated for $\mathrm{C}_{29} \mathrm{H}_{40} \mathrm{O}_{7} \mathrm{Na}$ 523.2666, found 523.2669. 